\title{
Back Pain and Radiculopathy from Non-Steroidal Anti-Inflammatory Drug-induced Dorsal Epidural Haematoma
}

\author{
Jaime L Martinez Santos, Mohammed Alshareef, Stephen P Kalhorn
}

Division of Neurosurgery, Department of Neurosciences, Medical University of South Carolina, Charleston, South Carolina, USA

Correspondence to Dr Jaime L Martinez Santos, martinezj@musc.edu

Accepted 27 February 2019

\section{DESCRIPTION}

We present a case of a previously healthy 29-year-old man who presented to the emergency department with a 2 -week history of low back pain and a sudden onset of right lateral leg pain with radiation to the dorsum of the foot and the big toe, consistent with L5 radiculopathy. On examination, he had full $5 / 5$ strength in all muscle groups, but had diminished light touch and pin prick sensation in the lateral surface of his right leg and dorsum of his right foot. He had no saddle anaesthesia or sphincter disturbance. On questioning, the patient reported taking extremely high doses of naproxen (500 mg every 4 hours or $3000 \mathrm{mg}$ per day) for at least 2 days and having no obvious drug-related side effects. He had no family history of bleeding diathesis, he was not on any antiplatelet or

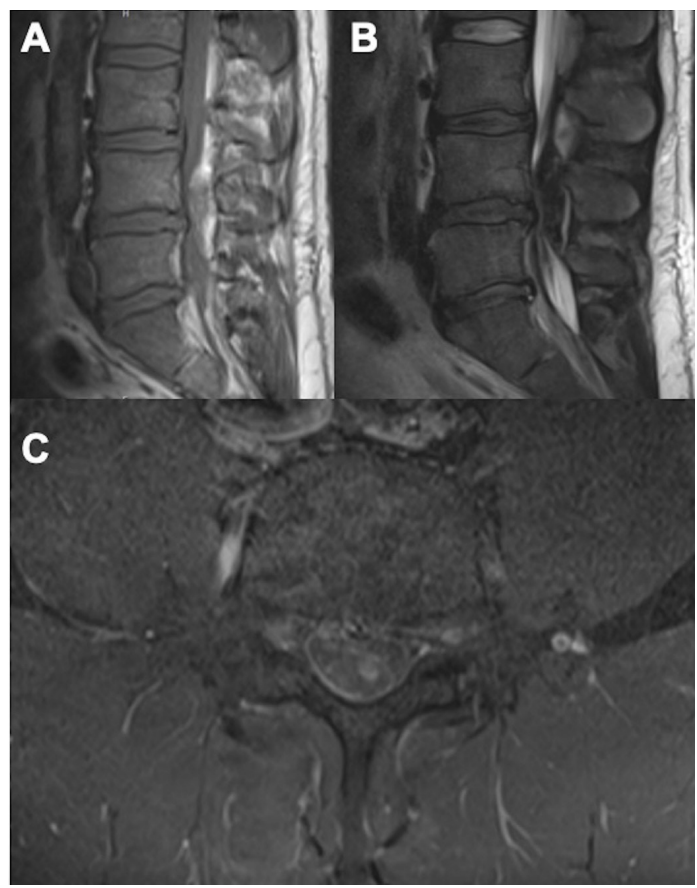

Figure 1 Lumbar spine MRI. (A) Sagittal T1 MRI shows an L4-5 large dorsal compressive epidural lesion, with heterogeneous intensity. (B) Sagittal T2 MRI shows the same lesion (arrowhead) which appears hypointense with severe canal stenosis and compression of the thecal sac. (C) Axial MRI with contrast (gadolinium) reveals enhancing capsule surrounding the non-enhancing mass (arrow). This was thought to be a haematoma versus haematological malignancy.

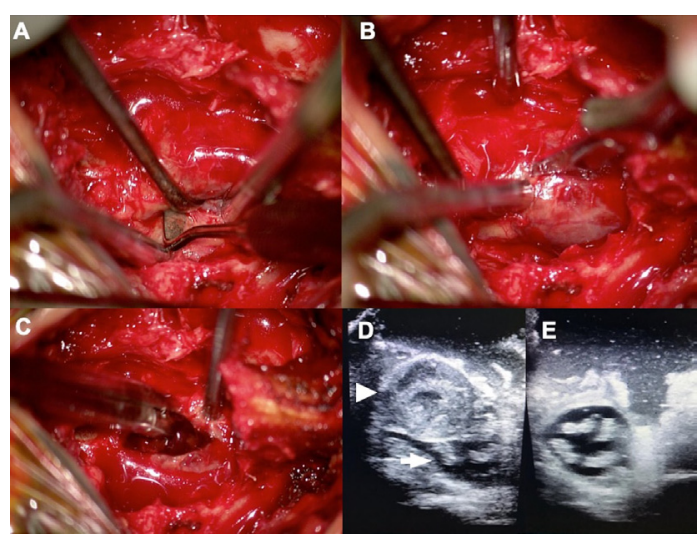

Figure $2(A-C)$, Intraoperative microphotographs showing dissection along the interface between the haematoma and the dorsal dura or thecal sac $(A)$; and haematoma evacuation (B,C). (D) Intraoperative ultrasound (IOUS) image showing the haematoma (arrowhead) causing compression on the thecal sac and nerve roots (arrow). (E) IOUS after haematoma evacuation showing an adequately decompressed and re-expanded thecal sac.

anticoagulant therapy, and he had normal platelet count and coagulation laboratory panels.

MRI of his lumbar spine (figure 1) revealed a dorsal T1 hyperintense, and T2 hypointense mass spanning L4 and L5 with a homogeneously enhancing capsule. Findings were consistent with subacute haematoma. A diagnostic spinal angiogram was negative for spinal arteriovenous malformation or other vascular aetiology for this haematoma. The patient underwent laminectomy and complete haematoma evacuation (figure 2A-C) confirmed with intraoperative ultrasound (IOUS; figure 2D-E). He had immediate symptom resolution and uneventful follow-up. Pathology of the clot and pseudocapsule were sent which were negative for neoplasm and consistent with blood products. We did not encounter excessive bleeding in surgery with an estimated blood loss of less than $20 \mathrm{~mL}$.

There are three types of spinal epidural haematomas: iatrogenic, traumatic and spontaneous. Spontaneous spinal epidural haematomas (SSEDH) are very rare and represent less than $1 \%$ of all spinal space-occupying lesions. ${ }^{1}$ Common aetiologies and risk factors include vascular malformations (including arteriovenous malformations and vertebral body haemangiomas), anticoagulant or antiplatelet use, coagulopathy, platelet disorder and 
neoplasia. ${ }^{1-4}$ Patients almost universally develop a sudden onset of severe back pain that if left untreated is followed by myelopathy or radiculopathy, depending on the spinal level, and possibly sphincter disturbance.

SSEDH tend to occur at the more mobile spine segments ${ }^{2}$ such as the lumbar and cervical spine, and their transition zones. It has been postulated that the bleeding epicentre is from Batson's internal vertebral venous plexus and its tributaries. ${ }^{12}$ In most cases, the haematoma is located dorsally in the epidural space because the plexus at that location is more prominent, and the venous tributaries have fewer supporting structures, especially midline where there is no interlaminar ligament and congestion

\section{Learning points}

The hallmark of every spinal epidural haematomaspontaneous or postsurgical-is always severe back pain that is 'out of proportion'.

- Patients with back pain may consume large amounts of nonsteroidal anti-inflammatory drugs for pain relief as they are cheap and accessible. The clinician should always inquire about this during history taking.

- Prompt diagnosis of spinal epidural haematoma and neurosurgical intervention improve functional outcomes.

- Intraoperative ultrasound can aid in localising the haematoma and confirm adequate decompression. ensues more easily. Treatment is surgical but in some selective cases, conservative management with serial surveillance imaging and frequent neurological examinations is an alternative. We recommend using IOUS in all cases of spinal haematomas. IOUS helps identify the dura and neural elements and aids in localising the haematoma rostrocaudally. Furthermore, IOUS can be used to locate haematomas in obscure spaces such as intradurally, given that cases with intradural haematoma extension are possible. Lastly, we advocate using IOUS at the end of the case to confirm resolution of mass effect.

Contributors JLMS and SPK contributed to the conception and design of this study. JLMS and MA drafted the manuscript and JLMS, MA and SPK revised it critically and made corrections. JLMS, SPK and MA approved the final version. JLMS obtained consent for this publication.

Funding The authors have not declared a specific grant for this research from any funding agency in the public, commercial or not-for-profit sectors.

Competing interests None declared.

Patient consent for publication Obtained.

Provenance and peer review Not commissioned; externally peer reviewed.

\section{REFERENCES}

1 Al-Mutair A, Bednar DA. Spinal epidural hematoma. J Am Acad Orthop Surg 2010;18:494-502.

2 Figueroa J, DeVine JG. Spontaneous spinal epidural hematoma: literature review. J Spine Surg 2017;3:58-63.

3 Zhong W, Chen H, You C, et al. Spontaneous spinal epidural hematoma. J Clin Neurosci 2011;18:1490-4.

4 Dziedzic T, Kunert P, Krych P, et al. Management and neurological outcome of spontaneous spinal epidural hematoma. J Clin Neurosci 2015;22:726-9.

Copyright 2019 BMJ Publishing Group. All rights reserved. For permission to reuse any of this content visit

https://www.bmj.com/company/products-services/rights-and-licensing/permissions/

BMJ Case Report Fellows may re-use this article for personal use and teaching without any further permission.

Become a Fellow of BMJ Case Reports today and you can:

- Submit as many cases as you like

- Enjoy fast sympathetic peer review and rapid publication of accepted articles

- Access all the published articles

- Re-use any of the published material for personal use and teaching without further permission

For information on Institutional Fellowships contact consortiasales@bmjgroup.com

Visit casereports.bmj.com for more articles like this and to become a Fellow 